\title{
'DIFFERENTIAL POVERTY RATES ARE RESPONSIBLE FOR THE RACIAL DIFFERENTIALS IN HIV PREVALENCE IN SOUTH AFRICA': AN ENDURING AND DANGEROUS EPIDEMIOLOGICAL URBAN LEGEND?
}

\author{
Chris Kenyon, $M B C h B, B A$ (Hons), $M P H, F C P$ \\ Division of Infectious Diseases and HIV Medicine Unit, Department of Medicine, University of Cape Town
}

\begin{abstract}
It is widely held to be axiomatic in South African epidemiological and social science circles that it is not worth comparing the risk factors underpinning the dramatic differences in HIV spread in South Africa's racial groups, as these are all explained by corresponding differences in socio-economic status. The available evidence, however, suggests that HIV is not simply contoured along lines of socio-economic deprivation; rather, other - largely culturally determined - factors such as the practice and acceptance of multiple concurrent sexual partnerships play a key role. Comparison of sexual behaviours between South Africa's different races supports the likelihood that cultural and not socio-economic factors are the mediators of differential racial HIV spread. Finally, it is argued that the failure of many South African experts in the study of HIV to consider race as a valid variable for analysis, and allied to this their continued exaggeration of the importance of socio-economic rather than cultural factors, has contributed to the relative failure of our national AIDS strategy.
\end{abstract}

With the aim of presenting an overview of the key literature that analyses the relationship between class, race, culture and HIV in South Africa, a literature review was conducted using Pubmed and Google Scholar to search for the following key words: 'South Africa', 'socioeconomic status', 'socioeconomic', 'poverty', 'wealth', 'education', 'HIV prevalence', 'HIV risk' and 'sexual behaviour'.

\section{THE ARGUMENT THAT CLASS DETERMINES} RACIAL DIFFERENCES IN HIV PREVALENCE

A salient feature of the literature on this topic is how commonly it is assumed (with little or no substantiating evidence) that racial differences in HIV rates in South Africa can all be explained by socio-economic differentials. According to one of the premier textbooks on HIV/AIDS in South Africa, the reason HIV prevalence rates differ between races is that 'marginalisation and discrimination on the basis of race and/or ethnicity are key factors influencing vulnerability to HIV infection' (p. 63).' Similarly, Mitton's paper entitled 'The sociological spread of HIV/AIDS in South Africa' argues that AIDS is 'primarily an illness of marginalised persons' and hence has spread faster among black Africans due to their marginalised position in apartheid society. ${ }^{2}$ No evidence is provided in either of these two pieces to back up these claims.
A more convincing argument is that HIV is a disease of poverty and inequality, and black Africans' ongoing state of economic deprivation (both relative and absolute) is the underlying determinant of the racial divergences in HIV rates. In many of the articles that make this argument no empirical evidence is provided. As an example, McCoy et al. claim without any supporting evidence that 'critically the profound link between AIDS and poverty must be recognised and broken [in dealing with South Africa's HIV epidemic].' A further example is Gilbert and Walker's 'Treading the path of least resistance: HIV/AIDS and social inequalities - a South African case study'. Here an unreferenced assertion is simply made that 'there is a strong link between low income, high unemployment and poor education ... and rates of HIV infection' (p. 1106). ${ }^{4}$ Other papers which assume that socio-economic factors determine racial differential HIV rates include those by $\mathrm{Tladi}^{5}{ }^{5}$ Phatlane $^{6}{ }^{6}$ Cunha $^{7}$ and Marks. ${ }^{8}$

An urban legend can be defined as 'a story or anecdote that is based on hearsay and widely circulated as true.' Characteristically, when the storyteller is questioned as to the evidence backing up the story they claim that there were eye-witnesses, but when pressed it emerges that these were friends of friends. In a similar vein, one of the striking features of the above-quoted papers is how they either present no evidence or references 
to back up their claims or else refer to other papers that have no empirical data to substantiate their assertions.

An exception to this is a paper by Fassin and Schneider, $^{10}$ which argues that 'social inequalities in income and employment status' are, together with sexual violence and enhanced mobility, the three social factors responsible for the magnitude of South Africa's epidemic. They provide evidence to back up the assertion that 'social inequalities in income and employment status are powerful predictors of HIV infection' in the form of a study in a mining company that stratified HIV status by race and occupational status (Fig. 1). The authors claim that the higher HIV rates in blacks than whites, and in the unskilled versus the skilled job categories, are 'the legacy of centuries of colonial exploitation and racial segregation, culminating in the institution of apartheid in the second half of the 20th century'. Their argument is that 'epidemiologically this segregation translates as differential HIV seroprevalence between black and white groups and between social classes'. They do not, however, comment on why the HIV rate within each occupational stratum is so much higher in the black than the white workers. As an example, within the lowest job category, the HIV rate is five times higher in blacks than whites. The original authors of the study note that this patterning does not support the hypothesis that socio-economic differentials determine racial differences in HIV. ${ }^{11}$

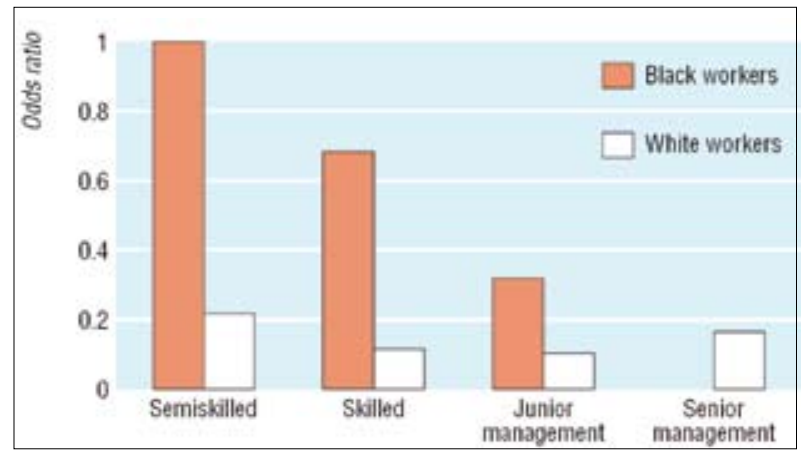

Fig. 1. Odds ratios for HIV prevalence among employees in South Africa. ${ }^{10}$

One of the most compelling proponents of the povertyinequality thesis is the anthropologist Mark Hunter. He too is unable to provide much empirical evidence to back up his engaging ethnographic material. One of the few pieces of quantitative evidence he does advance is that HIV incidence and prevalence rates are higher in informal than formal settlements in South Africa. ${ }^{12}$ This is based on the 2005 Human Sciences Research Council (HSRC) HIV survey. ${ }^{13}$ There is, however, not much one can conclude from the fact that HIV prevalences in formal and informal urban settlements are 9\% and $17 \%$ respectively, when no attempt is made to control for the fact that race (which was itself strongly correlated with HIV status) co-varies with type of urban settlement.

\section{HOW IS HIV CONTOURED ALONG THE LINES OF RACE AND CLASS IN SOUTH AFRICA?}

Johnson, Budlender and Kirk have undertaken much more thorough analyses of the relationship between income, race and HIV. Kirk ${ }^{14}$ analysed South Africa's national antenatal clinic HIV survey data to try to tease out the relationship between income, race and HIV. Unfortunately the antenatal survey does not collect information about income, but Kirk was able to use other data sources to show that the level of poverty in a magisterial district is negatively associated with the HIV prevalence among women attending antenatal services in that district. This finding was backed up by his analysis, which found that women with no education are at a lower risk of HIV infection than women who received high-school education (women with university education had the lowest HIV rates). Johnson and Budlender's review of this topic demonstrates some of the complex ways in which race, class and culture interact to produce South Africa's HIV epidemic. ${ }^{11}$ One of these pieces of evidence is their presentation of a multivariate logistic regression analysis of the antenatal clinic data to reveal that racial differences persist despite controlling for socio-economic status (which was done here by using education level) (Table I).

TABLE I. ODDS RATIOS FOR HIV INFECTION IN DIFFERENT RACE GROUPS BASED ON A MULTIVARI-

ATE ANALYSIS OF THE 1998 AND 1999 HIV ANTENATAL SURVEY DATA ${ }^{11}$

\begin{tabular}{|lcl|} 
& Odds ratio & $\boldsymbol{p}$-value \\
\hline African & 1 & - \\
Asian & 0.23 & 0.05 \\
Coloured & 0.17 & $<0.001$ \\
White & 0.13 & $<0.001$ \\
\hline
\end{tabular}

Three more recent studies from South Africa have confirmed the finding that HIV is not simply a disease of poverty. Using a cohort study of 3881 individuals in eight villages in rural South Africa between 2001 and 2004, Hargreaves et al. were able to show that there was no association between HIV incidence and household wealth for the men and women. ${ }^{15}$ Less educated women did, however, have a higher rate of infection. In the second study, Barnighausen et al. used data from a longitudinal HIV surveillance and linked demographic surveillance in rural KwaZulu-Natal to test the relationship between socio-economic status, education and HIV incidence. ${ }^{16}$ HIV incidence was found to be related to household wealth - with the incidence lowest in the low- and high-wealth brackets and highest in the middle-income bracket. Education level in this study was found to be associated with a lower risk of acquiring HIV. Likewise, the Carltonville Project found no difference in HIV prevalence between the employed and the unemployed. ${ }^{17}$ Finally, a cluster randomised 
trial designed to evaluate the impact of a microfinance lending scheme on HIV incidence found it had no impact despite improving the economic wellbeing of the participants. ${ }^{18}$

There is conflicting evidence regarding the extent to which HIV knowledge or risky behaviour varies by socioeconomic status. A multivariate study using data from the 1998 South African Demographic and Health Survey found 'little evidence that poverty is associated with risky sexual behaviour'. Poorer women were, however, slightly less likely to have the necessary knowledge about HIV. ${ }^{19}$ In contrast, Hallman, using household survey data from 14 - 24-year-olds in Kwazulu-Natal, showed that among females but not males low wealth is associated with earlier sexual debut, having had multiple sexual partners in the year before the survey, and lower chances of condom use at last sex. ${ }^{20}$

One of the reasons why South Africans are still debating whether HIV is or is not a disease of poverty may relate to the poor quality of our national surveys. This is illustrated by the way that good-quality evidence from elsewhere in Africa has established that 'HIV infection does not disproportionately affect the poorer in sub-Saharan Africa'. ${ }^{21}$ This was the title of a paper that published the results of eight national HIV-serolinked demographic surveys. The most salient finding was that in all eight countries, adults in the wealthiest quintiles had a higher prevalence of HIV than those in the poorer quintiles. There was a step-wise increase in HIV with wealth quintiles in most cases. Three other HIVserolinked demographic studies, from Kenya, ${ }^{22}$ Tanzania $^{23}$ and Burkino Faso, ${ }^{24}$ have produced similar results (Fig. 2). A review article from the 'Poverty, Wealth and HIV' supplement in the journal AIDS concluded that poor individuals are not necessarily more likely to be exposed to HIV and therefore 'AIDS cannot accurately be termed a disease of poverty' (p. S15). ${ }^{25}$

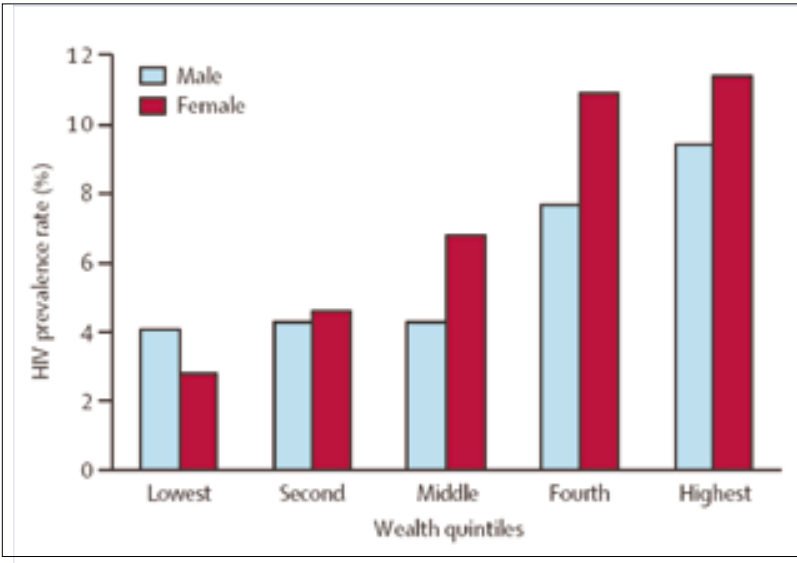

Fig. 2. HIV prevalences for males and females by wealth quintiles in Tanzania. ${ }^{45}$

So what do the equivalent South African sero-surveys tell us about the relationship between HIV, wealth, race and sexual behaviours in South Africa? Remark- ably little. The HSRC is the only body that has received funding to conduct nationally representative serolinked surveys of all South Africans. It has conducted three such surveys, in 2002, 2005 and 2008. By tracking knowledge, sexual behaviours and HIV prevalence, the HSRC surveys are supposed to be South Africa's flagship surveys to track progress in dealing with our epidemic. Unfortunately, the surveys fail to a considerable extent on all three accounts. Knowledge about HIV and its prevention, we are told, has declined from 2002. It is, however, hard to interpret what this means, given the ambiguities associated with one of the two questions assessing HIV knowledge: 'To prevent HIV infection, a condom must be used for every round of sex?' If a mutually monogamous couple with no recent other relationships has undergone couple HIV testing and both are negative, they would be quite correct to answer 'no' to this question. According to the HSRC they would score zero for this answer. Sexual behaviours are tracked, but nowhere in any of the HSRC surveys is sexual partner concurrency (arguably the key risk factor in our setting) evaluated in any way. In the last survey we are informed that the percentage of persons who had more than one sexual partner in the past year is 'a factor contributing to concurrent sexual partnerships' (p. 41). This factor is then used as a surrogate for concurrency. No evidence is provided to back up this assumption.

Arguably the most marked inadequacy in the three HSRC surveys is how poorly the epidemic is mapped. Sexual behaviour surveys in the USA, such as the National Health and Social Life Survey (NHSLS), have found that 'the vast majority of sexual partnerships originate within tightly circumscribed social settings, resulting in partnerships involving persons with similar characteristics' (p. 255). ${ }^{26}$ Most sexual partnerships and marriages therefore occur within the same racial/ ethnic, class, age and religion categories. This effect is strongest for race/ethnic group. The NHSLS found that 91\% of short-term relationships and 93\% of marriages were between persons of the same racial/ethnic group. It would be very useful to know if this is the case, as seems likely, in South Africa, but this kind of basic information was not assessed in the HSRC surveys. For similar reasons, the HSRC surveys are unable to break the epidemic down by socio-economic status or education levels - except to show that HIV rates are higher in informal than formal settlements. In their current format our surveys are simply not able to answer the most basic questions such as the relationship between HIV, income and race. In fact, race seems an almost taboo variable in the surveys. At no stage, for example, are sexual behaviours compared between racial groups. In the 2008 survey, there is only one place in the 120page report where HIV rates are broken down by race in a small table in Appendix A, where overall HIV rates in each racial group are presented. 
If we cannot explain South Africa's racial differences in HIV by economic differentials, then how can we? An obvious, if rather simplistic, way to examine this question is to compare sexual behaviours between the races premised on the fact that HIV is spread by sex and more specifically via sex networks. Comparing sex networks is especially important, since differences in network structure are more likely to explain large differences in HIV rates than individual level differences. Network level differences, for example, have been shown to explain a third of the difference in sexually transmitted infections between races in the USA. ${ }^{27}$ We were unable to find a single published study that makes a comprehensive comparison of sexual behaviours in different racial groups in South Africa. We therefore conducted an analysis of a representative sample of 353114 25-year-old Cape Town inhabitants in the Cape Area Panel Survey (CAPS). Individual level behavioural risk factors did not vary much by race (in fact, the lifetime number of sexual partners was highest in the white group). However, this was not the case for network factors. Blacks were much more likely to have engaged in concurrency themselves or to have a partner who engaged in concurrency (Table II). ${ }^{28}$

Various lines of evidence have supported the importance of concurrency in HIV spread in this area. Numerous epidemiological studies have shown a strong link between partner concurrency and the incidence of sexually transmitted infections. ${ }^{29-31}$ The most compelling difference in sexual behaviours between high- and low-prevalence HIV countries globally is that sexual partner concurrency is far more prevalent in the highincidence countries of southern and eastern Africa. ${ }^{32,33}$ Modelling exercises have shown that the key way concurrency increases HIV transmission is at a network lev$\mathrm{el}$, where it increases the network interconnections in a manner that creates 'superhighways' for HIV spread. ${ }^{34}$ In this way concurrency increases HIV transmission exponentially - even if the number of sex partners does not increase.

What then are the underlying reasons for the racial differences in sexual behaviour in South Africa - in this case, the elevated concurrency rates in blacks? Two main categories of factors have been advanced as being important in the promotion of high concurrency rates - cultural and socio-economic factors. In a separate study looking at the determinants of concurrency in the CAPS dataset, we found that the relationship between income quintile and concurrency found on univariate analysis disappeared on multivariate analysis. ${ }^{35}$ In addition, when we broke concurrency rates down by income quintile for each race and gender, there was no relationship between concurrency and income in any of these groups. This supports the view that, as in Uganda, it is cultural factors which are responsible for the high concurrency rates. ${ }^{36}$ Indeed, the ' 10 Countries' study found that a crucial factor underpinning high concurrency rates in the 10 countries in southern and eastern Africa was that it was regarded as normative for men to have multiple concurrent partners. ${ }^{37}$

It is important to acknowledge three important caveats to the findings presented here. Firstly, the analyses presented have attempted to ascertain the relationship between poverty and HIV. No studies in South Africa that we are aware of have examined the role of socioeconomic inequalities in HIV spread. Secondly, we cannot exclude the possibility that high poverty rates over generations may have had an effect on producing a set of enduring norms pertaining to sexual behaviour in blacks which, due to its population level effect, applies as much to wealthier blacks. This would mean that analyses such as our CAPS data, which controlled for wealth using contemporary levels of wealth, are unable to discern this legacy-of-poverty effect. Thirdly, there is good evidence that the HIV epidemic is following the pattern of many other behaviour-related diseases (such as smoking-related ones) which were more prevalent among the wealthy in the early stages, but became more prevalent among the poor as knowledge of the ill effects gathers. ${ }^{38}$

\section{SHOULD WE DOWNPLAY WHAT IS PSYCHOLOGICALLY PAINFUL?}

The HSRC Survey of 2005 revealed HIV prevalences of $19.9 \%, 3.2 \%$ and $0.5 \%$ for 15 - 49-year-old blacks, coloureds and whites, respectively. ${ }^{13}$ The racial differ-

TABLE II. CONCURRENCY RATES BY RACE AMONG 14 - 25-YEAR-OLD CAPETONIANS ${ }^{26}$

\begin{tabular}{|lccc|} 
& Blacks (\%) & Coloureds (\%) & Whites (\%) \\
\hline Partner engaged in concurrency & 33 & 13.2 & 11.9 \\
Any partner definitely or possibly had concurrent partner & 68.2 & 34.9 & 25.9 \\
Interviewee has had two sexual relationships simultaneously at some stage & 30.1 & 10.8 & 4.9 \\
Respondents who have had 1, 2 or $\geq 3$ concurrent relationships: & & \\
1 & 19.1 & 5.9 & 4.5 \\
2 & 7.2 & 1.3 & 0.6 \\
$\geq 3$ & 2.0 & 0.5 & 0.6 \\
Concurrently concurrent & 15.3 & 2.7 & 1.3 \\
More than one partner had a concurrent relationship & 10.8 & 3.1 & 2.4 \\
\hline
\end{tabular}


ences in HIV within South Africa are therefore similar in magnitude to those between the highest and lowest prevalence countries in the world. Finding the underlying determinants for these differences should therefore provide us with important clues as to the nature of the 'holy grail' in South African HIV research - what we need to do to stop the scandalously high current incidence rates. According to recently published data from a surveillance site in rural KwaZulu-Natal, 3.4\% of adults acquired HIV during 2008, and this incidence rate has not declined at all over the past 5 years. ${ }^{39}$ Our investigations along these lines provided strong support for the view that a (largely) culturally driven practice of concurrency was the likely key factor responsible for the elevated HIV rates seen in blacks. Although at the 4th SA AIDS Conference there was considerable interest in dealing with multiple concurrent partnerships, there still remains an embarrassing paucity of evidence that has been generated in South Africa on the link between concurrency and HIV transmission, and on the cultural and other factors responsible for our high concurrency rates.

As described above, part of the reason for this has been a peculiar reluctance to use race as an analytical variable as regards to HIV. The origins of this racial blind spot are not hard to fathom. Concepts of white racial and cultural superiority were central to the ideology of apartheid. Thabo Mbeki would later characterise this ideology as one where black people were made to feel 'their inferiority by being reminded of their role as germ carriers ... [and attend] schools where they learn a history that pictures black people as human beings of a lower order, unable to subject passion to reason: ${ }^{40}$ Given this background, when, in the early days of the new non-racial dispensation, a new and lethal disease that was sexually transmitted was found to disproportionately affect black South Africans, it should not be too surprising that the investigating experts biased their assessments of aetiology towards socio-economic factors. To suggest that cultural practices were responsible might have sounded at best insensitive and at worst racist. An example of these dynamics is a book published earlier this year by a respected South African professor of anthropology on the topic of how differences in sex networks explain the different HIV trajectories in Uganda and South Africa. ${ }^{41}$ In the preface, the author explains that he 'largely ignores race'; as he explains, 'it appears to me that with respect to sex and choice of sexual partners, race does not predict or determine significant social differences' (p. xviii). The only argument he produces to justify ignoring race is his rejection of apartheid, which sought to 'convince South Africans that they were more different from one another than they in fact are'. This belief, he explains, 'was empirically, not just morally, wrong. I treat South Africa as an African country and do not distinguish South Africans by race.' Despite sexual behaviour being one of the most culturally varied of all human behaviours ${ }^{42}$ and despite the abundant evidence of the striking differences in racial HIV rates, Thornton simply assumes there are no differences in the makeup of sexual networks by race in South Africa. Because we reject apartheid, his argument seems to be, we must ignore all the evidence to the contrary and simply assume away all racial differences in sexual behaviour and sex network makeup. Ironically, if this reluctance to venture into uncomfortable psychological spaces explains part of the origins of this denial of cultural/behavioural explanations for HIV's rapid spread in South Africa (termed third-generation denialism here), its origins have much in common with South Africa's more famous forms of HIV denialism. Both Mbeki's biological HIV denialism (a virus can't cause a syndrome) and his secondgeneration treatment denialism (which sought to encourage vegetables and vitamins over antiretrovirals) had their origins in a similar psychological process, which sought to downplay cognitions dissonant with his belief in the dawn of an African renaissance. ${ }^{43}$ More important than the similarity in their origins, however, is the similar effects that first- to third-generation denialism are having in undermining HIV prevention efforts. It is not just that the average South African does not have a good idea of which sexual behavioural factors are responsible for the high HIV rates, but an unacceptably high proportion of leaders and experts in the field do not either.

It is interesting to note how a country without this legacy of race-based conflict, such as Uganda, was able in a short space of time to undergo a process of painful introspection which correctly identified and successfully targeted the practices of multiple concurrent partnerships that were fuelling the epidemic. ${ }^{44}$ It is surely time for South Africa to rectify this blind spot and venture into the psychologically painful but productive places that Uganda did decades ago. One of the reasons why urban legends are believed and spread is because they construct and reinforce the conceptual framework of the group within which they are told. If we contrast the unquestioning acceptance of thepoverty-explains-racial-HIV-differences thesis with the amount of evidence underpinning it, then it follows that not only did its spread share certain features in common with urban legends, but as with urban legends, its spread reveals more about the psychologies of its followers than about the differential HIV spread it purported to explain.

\footnotetext{
REFERENCES

1. Gouws $E$, Abdool Karim Q. HIV infection in South Africa: the evolving epidemic In: Abdool Karim SS, Abdool Karim Q, eds. HIV/AIDS in South Africa. Cambridge: Cambridge University Press, 2005.

2. Mitton J. The sociological spread of HIV/AIDS in South Africa. Journal of the Association of Nurses in AIDS Care 2000; 11 (4):17-26.

3. McCoy D, Wood R, Dudley L, Barron P. South Africa: The HIV pandemic. In: Beck EJ, Mays N, Whiteside A, Zuniga JM, eds. The HIV Pandemic. Oxford: Oxford University Press, 2006.

4. Gilbert L, Walker L. Treading the path of least resistance: HIV/AIDS and social inequalities - a South African case study. Soc Sci Med 2002; 54(7): 1093-1110.
} 
5. Tladi LS. Poverty and HIV/AIDS in South Africa: an empirical contribution. Journal of Social Aspects of HIV/AIDS 2006; 3(1): 369-381.

6. Phatlane SN. Poverty and HIV/AIDS in Apartheid South Africa. Social Identities 2003; 9(1): 73-91.

7. Cunha M. South African politics, inequalities, and HIV/AIDS: Applications for public health education. Journal of Developing Studies 2007; 23(1-2): 207-219.

8. Marks S. 2002. An epidemic waiting to happen? The spread of HIV/AIDS in South Africa in social and historical perspective. African Studies 2002; 61(13): 13-26.

9. Mirriam-Websters Collegiate Dictionary. 11th ed. Springfield, III.: Miriam-Webster, 2003.

10. Fassin D, Schneider H.The politics of AIDS in South Africa: beyond the controversies. BMJ 2003; 326: 495-497.

11. Johnson L, Budlender D. HIV Risk Factors: A Review of the Demographic, Socioeconomic, Biomedical and Behavioural Determinants of HIV Prevalence in South Africa. Cape Town: Centre for Actuarial Research, University of Cape Town, 2002.

12. Hunter M. The changing political economy of sex in South Africa: The significance of unemployment and inequalities to the scale of the AIDS pandemic. Soc Sci Med 2007; 64: 689-700.

13. Shisana O, Rehle T, Simbayi LC, et al. South African National HIV Prevalence, HIV Incidence, Behaviour and Communication Survey, 2005. Cape Town: HSRC Press, 2005.

14. Kirk D. Risk factors associated with HIV prevalence. Honours research project, Department of Actuarial Science, University of Cape Town, 2001.

15. Hargreaves JR, Bonell $C P$, Morison LA, et al. Explaining continued high HIV prevalence in South Africa: Socioeconomic factors, HIV incidence and sexual behaviour change among a rural cohort, 2001 - 2004. AIDS 2007; 21 (suppl. 7): S39-S48.

16. Barnighausen $T$, Hosegood $V$, Timaeus $I M$, Newell $M$. The socioeconomic determinants of HIV incidence: evidence from a longitudinal, population-based study in rural South Africa. AIDS 2007: 21 (suppl. 7): S29-S38.

17. Williams BG, Gilgen D, Campbell CM, Taljaard D, MacPhail C. The Natural History of HIV/AIDS in South Africa: A Biomedical and Social Survey. Johannesburg: CSIR, 2000.

18. Pronyk, PM, Hargreaves JR, Kim JC, et al. Effect of a structural intervention for the prevention of intimate-partner violence and HIV in rural South Africa: a cluster randomised trial. Lancet 2006; 368: 1973-1983.

19. Le Booysen F, Sumerton J. Poverty, risky sexual behaviour, and vulnerability to HIV infection: evidence from South Africa. J Health Popul Nutr 2002; 20(4): 285-288.

20. Hallman K. Gendered socioeconomic conditions and HIV risk behaviours among young people in South Africa. African Journal of AIDS Research 2005; 4(1): 37-50.

21. Mishra $V_{1}$ Assche SB-V, Greener $R$, et al. HIV infection does not disproportionately affect the poorer in sub-Saharan Africa. AIDS 2007; 21 (suppl. 7): S17-S28.

22. Johnson K, Way A. Risk factors for HIV infection in a national adult population: evidence from 2003 Kenya Demographic and Health Survey. J Acquir Immune Defic Syndr 2006; 42: 627-636.

23. Tanzania Commission for AIDS (TACAIDS), National Bureau of Statistics (NBS) and ORC Macro. Tanzania HIV/AIDS Indicator Survey 2003-04. Calverton, Md: TACAIDS, NBS, and ORC Macro, 2005.

24. Lachaud JP. HIV prevalence and poverty in Africa: micro- and macro-econometric evidences applied to Burkina Faso. J Health Econ 2007; 26: 483-504.

25. Gillespie $\mathrm{S}$, Kadiyala $\mathrm{S}$, Greener R. Is poverty or wealth driving HIV transmission? AIDS 2007: 21 (suppl. 7): S5-S16.

26. Laumann EO, Mahay J, Paik M. Network data collection and its relevance for the analysis of STDs: The CHSLS and the NHSLS. In: Morris M, ed. Network
Epidemiology. Oxford: Oxford University Press, 2004.

27. Laumann EO, Youm Y. Racial/ethnic/ethnic group differences in the prevalence of sexually transmitted diseases in the United States: A network explanation. Sex Transm Dis 1999; 26(5): 250-261.

28. Kenyon C, Dlamini S, Boulle A, White R, Badri M. 2009. A network leve explanation for the differences in HIV prevalence in South Africa's racial/ethnic groups. African Journal of Aids Research 2009; 8(3): 243-254.

29. Ghani AC, Swinton SJ, Garnett GP. The role of sexual partnership networks in the epidemiology of gonorrhea. Sex Transm Dis 1997; 24(1): 45-56.

30. Potterat JJ, Zimmerman-Rogers HZ, Muth SO, et al. Chlamydia transmission: concurrency, reproduction number, and the epidemic trajectory. Am J Epidemio 1999; 150(12): 1331-1339.

31. Kenyon C, Badri M. The role of concurrent sexual relationships in the spread of sexually transmitted infections in young South Africans. Southern African Journa of HIV Medicine 2009; Summer, 29-36

32. Wellings $\mathrm{K}$, Collumbien $\mathrm{M}$, Slaymaker $\mathrm{E}$, et al. Sexual behaviour in context: a global perspective. Lancet 2006; 368: 1706-1728.

33. Halperin DT, Epstein H. Why is HIV prevalence so severe in southern Africa? The role of multiple concurrent partnerships and lack of male circumcision: Implications for AIDS prevention. Southern African Journal of HIV Medicine 2007 26: 19-23.

34. Morris $M$, Kretzschmar M. Concurrent partnerships and the spread of HIV. AIDS 1997; 11(5): 641-648.

35. Kenyon C, Boulle A, Badri M, Asselman V. I don't use a condom (with my regular partner) because I know that I'm faithful, but with everyone else I do': the cultura and socioeconomic determinants of sexual partner concurrency in young South Africans. Presented at the IAS Conference, 19 - 22 July 2009, Cape Town. Abstract No. MOPECO22

36. Epstein H. The Invisible Cure: Africa, the West and the Fight against AIDS. London: Penguin, 2007.

37. Jana $M$, Nkambule $M$, Tumbo $D$, Goldstein $S$, Weiner $R$, for The Soul City Institute Regional Programme (2007). One love: Multiple and concurrent sexual partnerships in southern Africa. A Ten Country Research Report. http://www.soulcity.org.za/ programmes/research/research-reports (accessed 20 June 2009).

38. Lopman B, Lewis J, Nyamukapa C. HIV incidence and poverty in Manicaland Zimbabwe: is HIV becoming a disease of the poor? AIDS 2007; 21 (suppl 7): S57S66.

39. Bärnighausen T, Tanser F, Newell ML. Lack of a decline in HIV incidence in a rural community with high HIV prevalence in South Africa, 2003 - 2007. AIDS Res Hum Retroviruses. 2009; 25(4): 405-409.

40. Mbeki T. ZK Matthews Memorial Lecture, University of Fort Hare, Alice, South Africa, 12 October 2001.

41. Thornton RJ. Unimagined Community: Sex, Networks and AIDS in Uganda and South Africa. London: University of California Press, 2008.

42. Youm $Y$, Paik A. The sex market and its implications for family formation. In: Laumann EO, Ellingson S, eds. The Sexual Organization of the City. Chicago: University of Chicago Press, 2004.

43. Kenyon C. Cognitive dissonance as an explanation of the genesis, evolution and persistence of Thabo Mbeki's HIV denialism. African Journal of AIDS Research 2008. 7(1): 29-35.

44. Kirby $D$. Changes in sexual behaviour leading to the decline in the prevalence of HIV in Uganda: confirmation from multiple sources of evidence. Sex Transm Infect 2008; 84 (suppl. 2): ii35-41.

45. Shelton JD, Cassel MM, Adetunji J. Is poverty or wealth at the root of HIV? Lancet 2005; 366: 1057-1058 